\title{
Venovenous extracorporeal membrane oxygenation for patients with refractory coronavirus disease 2019 (COVID-19): Multicenter experience of referral hospitals in a large health care system
}

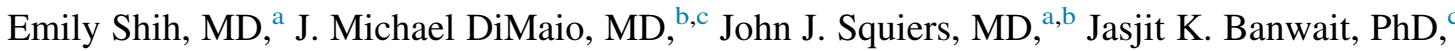
Dan M. Meyer, MD, ${ }^{\mathrm{d}}$ Timothy J. George, MD, ${ }^{\mathrm{b}}$ and Gary S. Schwartz, MD, ${ }^{\mathrm{d}}$ the Baylor Scott \& White ECMO for COVID Group

\section{ABSTRACT}

Background: The benefit of extracorporeal membrane oxygenation (ECMO) for patients with severe acute respiratory distress from coronavirus disease 2019 refractory to medical management and lung-protective mechanical ventilation has not been adequately determined.

Methods: We reviewed the clinical course of 37 patients with laboratory-confirmed severe acute respiratory syndrome coronavirus 2 infection supported by venovenous ECMO at $4 \mathrm{ECMO}$ referral centers within a large health care system. Patient characteristics, progression of hemodynamics and inflammatory markers, and clinical outcomes were evaluated.

Results: The patients had median age of 51 years (interquartile range, 40-59), and $73 \%$ were male. Peak plateau pressures, vasopressor requirements, and arterial partial pressure of carbon dioxide all improved with ECMO support. In our patient population, 24 of 37 patients $(64.8 \%)$ survived to decannulation and 21 of 37 patients $(56.8 \%)$ survived to discharge. Among patients discharged alive from the ECMO facility, 12 patients were discharged to a long-term acute care or rehabilitation facility, 2 were transferred back to the referring hospital for ventilatory weaning, and 7 were discharged directly home. For patients who were successfully decannulated, median length of time on ECMO was 17 days (interquartile range, 10-33.5).

Conclusions: Venovenous ECMO represents a useful therapy for patients with refractory severe acute respiratory distress syndrome from coronavirus disease 2019. (J Thorac Cardiovasc Surg 2022;163:1071-9)

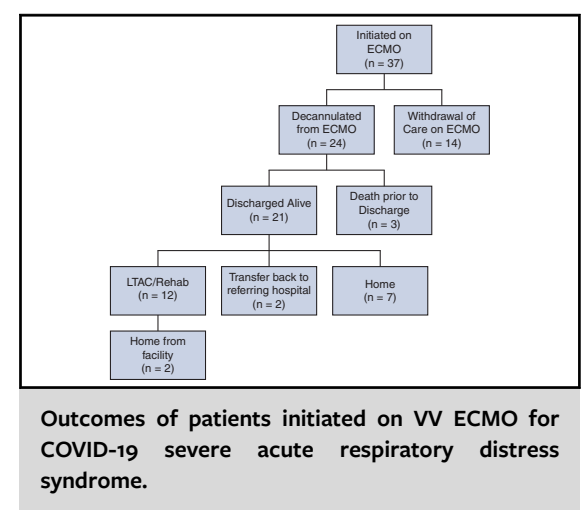

CENTRAL MESSAGE

ECMO represents a potentially useful therapy in patients with severe acute respiratory distress associated with refractory COVID-19.

\section{PERSPECTIVE}

The novel 2019 coronavirus disease (SARS-CoV2) has emerged as a serious public health threat. Respiratory failure refractory to lung-protective mechanical ventilation in select critical COVID19 cases has required experienced centers to deploy ECMO as a treatment modality. The benefit of ECMO for COVID-19 has not been adequately determined. Our study suggests that ECMO is a useful treatment option.

See Commentaries on pages 1080,1082 , and 1083

\footnotetext{
From the Departments of ${ }^{\mathrm{a}}$ General Surgery and ${ }^{\mathrm{d}}$ Cardiothoracic Surgery, Baylor University Medical Center, Dallas; ${ }^{b}$ Department of Cardiothoracic Surgery, Baylor Scott and White The Heart Hospitals, Plano; and ${ }^{\mathrm{c}}$ Baylor Scott and White Research Institute, Dallas, Tex.

Drs Shih and DiMaio contributed equally to this article.

Baylor Scott \& White ECMO for COVID Group authors: Britton A. Blough, MD, Robert L. Gottlieb, MD, PhD, Gonzo Gonzalez-Stawinski, MD, Anita R. Krueger, MD, Kara Monday, MD, Ramachandra C. Reddy, MD, Jorge F. Velazco, MD, Omar Hernandez, Chris Martin, Jenelle Sheasby
}

Received for publication July 7, 2020; revisions received Oct 24, 2020; accepted for publication Nov 1, 2020; available ahead of print Dec 1, 2020.

Address for reprints: J. Michael DiMaio, MD, Baylor Scott and White Research Institute, Dallas, TX (E-mail: michael.dimaio@bswhealth.org). $0022-5223 / \$ 36.00$

Copyright (C) 2020 by The American Association for Thoracic Surgery https://doi.org/10.1016/j.jtcvs.2020.11.073 


\begin{tabular}{|c|c|}
\hline \multicolumn{2}{|c|}{ Abbreviations and Acronyms } \\
\hline \multicolumn{2}{|c|}{$\begin{array}{l}\text { ADDreviations and Acronyms } \\
\text { ARDS = acute respiratory distress syndrome }\end{array}$} \\
\hline COVID-19 & $=$ coronavirus disease 2019 \\
\hline ECMO & $\begin{aligned}= & \text { extracorporeal membrane } \\
& \text { oxygenation }\end{aligned}$ \\
\hline $\mathrm{FIO}_{2}$ & $=$ fraction of inspired oxygen \\
\hline ICU & $=$ intensive care unit \\
\hline IL-6 & $=($ interleukin-6) \\
\hline IQR & $=$ interquartile range \\
\hline LOS & $=$ length of stay \\
\hline $\mathrm{PaO}_{2}$ & $=$ partial pressure of arterial oxygen \\
\hline SARS-CoV- & $\begin{aligned}= & \text { severe acute respiratory syndrome } \\
& \text { coronavirus } 2\end{aligned}$ \\
\hline VV & $=$ venovenous \\
\hline
\end{tabular}

\begin{tabular}{l} 
(4) $\begin{array}{l}\text { Scanning this QR code will take } \\
\text { you to the table of contents to } \\
\text { access supplementary informa- } \\
\text { tion. }\end{array}$ \\
\hline
\end{tabular}

The novel 2019 coronavirus (severe acute respiratory syndrome coronavirus 2 [SARS-CoV-2], the causative agent for coronavirus disease 2019 [COVID-19]) is a serious public health threat. The spectrum of manifestations ranges from asymptomatic spread to patients presenting with severe acute respiratory distress syndrome (ARDS) and multisystem organ failure. ${ }^{1}$ Venovenous (VV) extracorporeal membrane oxygenation (ECMO) has been implemented for severe ARDS with varying degrees of success over the last several decades. ${ }^{2}$ Referral to an ECMO center for consideration of initiation of ECMO was shown to be of benefit in patients with severe ARDS in the CESAR (Conventional Ventilatory Support Versus Extracorporeal Membrane Oxygenation for Severe Adult Respiratory Failure) trial, ${ }^{3}$ and ECMO was successfully used for patients with severe ARDS during the influenza (H1N1) pandemic. ${ }^{4}$ Thus, refractory ARDS with refractory severe hypoxemia or hypercarbia in critical COVID19 cases has prompted ECMO therapy in these patients as well. The benefit of ECMO for COVID-19 has not been adequately determined. Only scarce data are available regarding this population of patients, and rates of survival to discharge have been less than $20 \%$ in these reports. ${ }^{5-8}$ In this report, we describe the outcomes of a cohort of patients with severe COVID-19 who were initiated on ECMO at referral hospitals within a large health care system using stringent, objective criteria. These patients were not anticipated to survive without VV-ECMO.

\section{METHODS \\ Protocol}

We conducted a retrospective analysis of all patients from March 1, 2020 , to June 28, 2020, with laboratory-confirmed SARS-CoV-2 infection who were initiated on VV-ECMO support for refractory COVID-19 ARDS within the Baylor Scott \& White Healthcare System. The 4 hospitals acting as ECMO referral centers within the system contributed data to this study. The study was approved by the Baylor Scott \& White institutional review board. All authors were responsible for designing the study and for compiling and analyzing the data. The manuscript was prepared by the first authors and completed with input from all the authors, including the Baylor Scott \& White ECMO for COVID working group. Clinical data on patients cannulated during the study period were reviewed through October 21, 2020. At the time of analysis, all patients had been either discharged from the ECMO facility or were deceased.

\section{Patients}

All patients had laboratory-confirmed SARS-CoV-2 infection and were initiated on VV-ECMO support for COVID-19 ARDS. Two patients who were initiated on venoarterial ECMO support were excluded from the study. Daily ECMO and general critical care management were left to the discretion of the treatment team at each center, with system-wide ECMO protocols in place as guidance. Patients were managed by multidisciplinary teams, which included medical and surgical intensivists, cardiothoracic surgeons, ECMO specialists, infectious disease specialists, nephrologists, and other consultants as indicated. All patients underwent therapeutic anticoagulation per the system protocol and were monitored for bleeding. Patients were also weaned to decannulation in accordance with the system protocol. The clinical indications for ECMO, ECMO settings, anticoagulation protocol, and ECMO weaning protocol established by the Baylor Scott \& White ECMO Governance Council are detailed in Appendix E1.

\section{Outcome Measures}

The primary end point was survival to hospital discharge from the ECMO center. Secondary outcomes included overall survival at the time of analysis, death after withdrawal of care on ECMO, successful ECMO decannulation, survival to discharge after ECMO decannulation, duration of continuous ventilator support, duration of ECMO support, intensive care unit (ICU) and total hospital lengths of stay (LOS), need for concurrent interventions, and rates of complications potentially related to ECMO therapy. Data on patient's hemodynamics, ventilatorsupport requirements, laboratory values of interest, and concurrent COVID-19 therapies were also recorded on prespecified days before and during ECMO support.

Total continuous ventilator days, ICU LOS, and total hospital LOS were determined only from patients who survived to discharge. Total continuous ventilator days were calculated from the date of intubation (even if this occurred at another facility) until day of extubation at the study hospital. Total hospital LOS and ICU LOS were calculated by the total number of days the patients were admitted to the ICU and the hospital at the ECMO centers, respectively (not including days at another facility). Days on ECMO and ICU LOS were determined from the patients who were decannulated. Successful decannulation from ECMO was defined as freedom from ECMO without recannulation during the hospitalization. ARDS was defined according to the Berlin criteria. ${ }^{9}$ Coagulopathy was defined as an international normalized ratio greater than 3. Liver failure was defined as an alanine transaminase greater than 5 times the normal limit. Cardiogenic shock was defined as sustained systolic blood pressure $<90 \mathrm{~mm} \mathrm{Hg}$, cardiac index $<2.2 \mathrm{~L} / \mathrm{min} / \mathrm{m}^{2}$, or requirement for 2 or more inotropes. ${ }^{10}$ Bleeding was defined as new intracranial, gastrointestinal, cannulation site, or retroperitoneal hemorrhage while on ECMO. 


\section{Statistical Analysis}

Continuous variables were presented as the mean \pm standard deviation or as median with interquartile range (IQR), and categorical variables as proportions, unless otherwise specified. Competing outcomes were analyzed and graphed by adding the incidence of each outcome over time. The sum of proportions of patients reaching the indicated end points equals $1(100 \%)$ for each time point, and no patients were censored. Statistical analysis was performed using R (http://www.r-project.org). Confidence intervals were computed using Blaker's exact method for independent proportions.

\section{RESULTS \\ Patients}

From March 1, 2020, through June 28, 2020, a total of 2557 patients were hospitalized with laboratory-confirmed COVID-19 infection within the Baylor Scott \& White Healthcare System. Of these, 320 (12.5\%) were ultimately intubated for ventilatory support, and 37 patients $(11.6 \%$ of intubated patients; $1.4 \%$ of all COVID-19-positive patients) were placed on VV ECMO.

TABLE 1. Characteristics of patients with severe acute respiratory distress syndrome associated with refractory COVID-19 before venovenous ECMO cannulation including demographics, comorbidities, and clinical course before initiation of ECMO

\begin{tabular}{|c|c|}
\hline Median age, y (IQR) & $51(40-59)$ \\
\hline Male sex, $\mathrm{n}(\%)$ & $27 / 37(73)$ \\
\hline \multicolumn{2}{|l|}{ Ethnicity } \\
\hline Hispanic & $19 / 37(51)$ \\
\hline African American & $9 / 37(24)$ \\
\hline White & $6 / 37(16)$ \\
\hline Asian & $3 / 37(8)$ \\
\hline Body mass index, $\mathrm{kg} / \mathrm{m}^{2}$ & $33.9(30.6-37.9)$ \\
\hline \multicolumn{2}{|l|}{ Coexisting conditions, $\mathrm{n}(\%)$} \\
\hline Hypertension & 25/37 (67.6) \\
\hline Diabetes & 19/37 (51.4) \\
\hline Chronic obstructive pulmonary disease & $3 / 37(8.1)$ \\
\hline Active smoker & $1 / 37(2.7)$ \\
\hline End-stage renal disease on hemodialysis & $1 / 37(2.7)$ \\
\hline Immunodeficiency & $3 / 37(8.1)$ \\
\hline \multicolumn{2}{|l|}{ Admission setting, $\mathrm{n}(\%)$} \\
\hline Direct admission to ECMO center & $23 / 37(62.2)$ \\
\hline Transfer to ECMO center & $14 / 37(37.8)$ \\
\hline \multicolumn{2}{|l|}{ Pre-ECMO hospital course } \\
\hline Median days from admit to intubation (IQR) & $5(1-9.3)$ \\
\hline Median days from admit to ECMO (IQR) & $11.5(5-16)$ \\
\hline Median days from intubation to ECMO (IQR) & $4(2-11)$ \\
\hline Median days from SARS-CoV-2 confirmatory test to ECMO cannulation (IQR) & $11.5(5-14.5)$ \\
\hline Median days from symptom onset to ECMO cannulation (IQR) & $17(13-19.8)$ \\
\hline \multicolumn{2}{|l|}{ Other interventions before ECMO (\%) } \\
\hline Paralyzed & $31 / 37(83.8)$ \\
\hline Prone & 24/37 (64.9) \\
\hline CPR & $2 / 37(5.4)$ \\
\hline CRRT & $2 / 37(5.4)$ \\
\hline Intubated & $37 / 37(100)$ \\
\hline Vasopressors, n (\%) & $17 / 37(45.9)$ \\
\hline \multicolumn{2}{|l|}{ Initial cannulation site, $\mathrm{n}(\%)$} \\
\hline Internal jugular VV & $7 / 37(18.9)$ \\
\hline Bilateral femoral VV & $30 / 37(81.1)$ \\
\hline Initial cannulated at bedside, $\mathrm{n}(\%)$ & $37 / 37(100)$ \\
\hline Revision of cannula from bifemoral to internal jugular, $\mathrm{n}(\%)$ & $11 / 37(29.7)$ \\
\hline \multicolumn{2}{|l|}{ Conversion of ECMO } \\
\hline VV to VVA to VAV to VV & $1 / 37(2.7)$ \\
\hline
\end{tabular}


The characteristics of ECMO patients at baseline on admission to the hospital are summarized in Table 1. Median age was 51 years (IQR, 40-59 years), and 27 patients $(73 \%)$ were male. The majority were Hispanic $(51 \%)$ followed by African American (24\%), white (16\%), and Asian (8\%). The median body mass index of patients was $33.9 \mathrm{~kg} / \mathrm{m}^{2}$ (IQR, $30.6-37.9 \mathrm{~kg} / \mathrm{m}^{2}$ ). Hypertension was the most common coexisting medical condition $(67.6 \%)$, followed by diabetes $(51.4 \%)$, chronic obstructive pulmonary disease $(8.1 \%)$, active smoking $(2.7 \%)$, and end-stage renal disease on hemodialysis $(2.7 \%)$. There were 3 immunosuppressed patients $(8.1 \%)$ : 1 patient with a history of human immunodeficiency virus and 2 patients with history of organ transplant on immunosuppressive medications. Fourteen patients $(37.8 \%)$ had been directly admitted to one of the study centers, and $23(62.2 \%)$ patients were transferred to one of the referral centers from another facility specifically for ECMO evaluation and management. All transferred patients were cannulated at one of the referral centers.

Patients were admitted for a median length of 5 days (IQR, 1-9.3 days) before intubation and 11.5 days (IQR, 5-16 days) before initiation of ECMO. The median length of time to initiation of ECMO was 17 days (IQR, 1319.8 days) from reported symptom onset, 11.5 days (IQR, 5-14.5 days) from the first positive COVID-19 test, and 4 days (IQR, 2-11 days) from intubation. Before ECMO cannulation, 37 patients $(100 \%)$ were intubated, 31 patients $(83.8 \%)$ were paralyzed, 24 patients $(64.9 \%)$ were prone, 2 patients $(5.4 \%)$ had undergone cardiopulmonary resuscitation with return of spontaneous circulation, and 2 patients $(5.4 \%)$ were on continuous renal-replacement therapy. In addition, 17 patients $(45.9 \%)$ were on vasopressor support
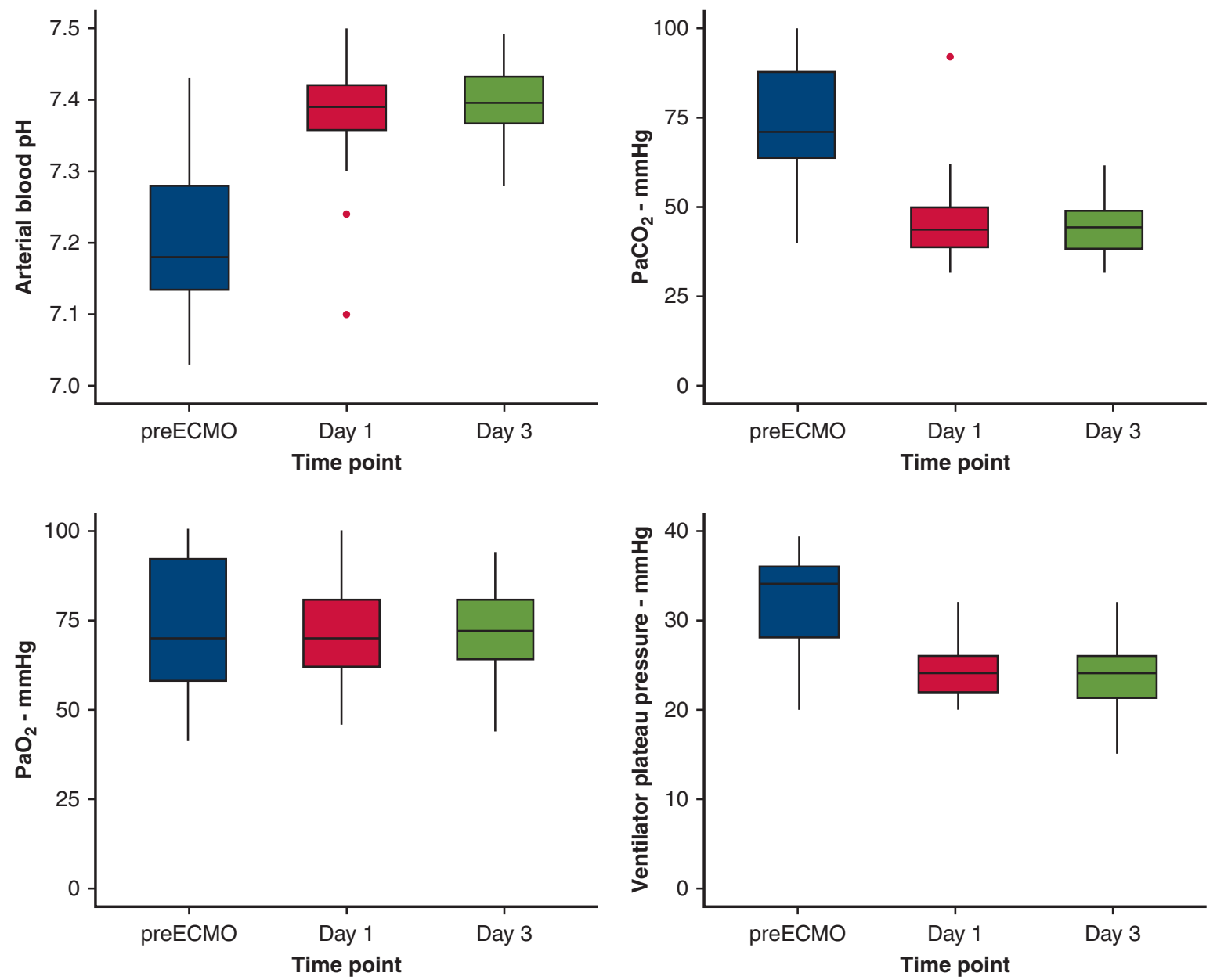

FIGURE 1. Trends of ventilatory measurements and arterial blood gas values of patients with severe acute respiratory distress syndrome associated with COVID-19 immediately before initiation on venovenous ECMO and on day 1 and 3 of ECMO support. There were statistically significant improvements in all values: A, arterial blood $\mathrm{pH}(P<.001)$; $\mathrm{B}, \mathrm{PaCO}_{2}(P=.007)$; $\mathrm{C}, \mathrm{PaO}_{2}(P<.001)$; and $\mathrm{D}$, ventilator plateau pressure in $\mathrm{mm} \mathrm{Hg}(P<.001)$. Data are presented as median (thick horizontal line), interquartile range (gray box), and 95\% confidence intervals (vertical lines) with outliers (red dots). All 37 patients in the study cohort had data available for every time point depicted. ECMO, Extracorporeal membrane oxygenation; $\mathrm{PaCO}_{2}$, partial pressure of carbon dioxide; $\mathrm{PaO}_{2}$, partial pressure of oxygen. 
at the time of ECMO initiation. Based on our centers' objective criteria for deployment of ECMO during the pandemic, including requirement to fail lung-protective ventilation strategies before advancing to ECMO, the clinically anticipated survival without ECMO in these patients was anticipated to be extremely low.

\section{ECMO Management}

All patients underwent initial cannulation at bedside rather than in the operating room. Initial cannulation sites were bifemoral in 30 patients $(81.1 \%)$ and right internal jugular dual lumen bicaval in 7 patients $(18.9 \%)$, with transesophageal echocardiography imaging guidance used in all cases. Eleven patients $(30 \%)$ underwent ECMO cannula revision: 10 were transitioned from bifemoral to right internal jugular dual lumen bicaval cannulation to improve mobility and 1 was revised from right internal jugular dual lumen to bifemoral cannulation due to cannula migration. Concurrent interventions during ECMO included continuous renal-replacement therapy (19 patients, 51\%) and chest tube placement (11 patients, 30\%).

\section{Medical Management of COVID-19}

While on ECMO, patients were treated for COVID-19 with hydroxychloroquine (17 patients, $45.9 \%$ ), azithromycin (20 patients, $54.1 \%$ ), anti-interleukin-6 receptor monoclonal antibody or placebo (25 patients double-blinded to drug vs placebo, $67.6 \%$ ), systemic corticosteroids (26 patients, $70.3 \%$ ), Remdesivir (20 patients, $54.1 \%$ ), systemic anticoagulation (37 patients, 100\%), and convalescent plasma ( 16 patients, $37 \%$ ). These therapies were administered according to various ongoing research protocols at the respective institutions and largely reflect the evolving treatment paradigms for COVID-19 during the study period.

\section{Hemodynamics and Inflammatory Markers}

The vital signs, inflammatory markers, and blood gas results immediately before ECMO cannulation and on ECMO days 1 and 3 were trended. The median partial pressure of arterial oxygen $\left(\mathrm{PaO}_{2}\right) /$ fraction of inspired oxygen $\left(\mathrm{FIO}_{2}\right) \mathrm{ra}-$ tio immediately before ECMO was 95 (IQR, 73-147), representing a median $\mathrm{PaO}_{2} / \mathrm{FIO}_{2}$ ratio consistent with severe ARDS by Berlin criteria. By the third day of ECMO support, mean ventilator plateau pressures improved after initiation of ECMO support (36 [IQR, 32.3-42.3] to 24 [IQR, 21.3-26] mm Hg; $P<.001)$; arterial blood $\mathrm{pH}$ normalized (7.2 [IQR, 7.1-7.3] to 7.4 [IQR, 7.4-7.4]; $P<.001$ ); and partial pressure of arterial carbon dioxide decreased (72.6 [IQR, 64.9-90] to 44.4 [IQR, 38.5-49] $\mathrm{mm} \mathrm{Hg} ; P=.007$ ) (Figure 1).

Most patients on vasopressor at the time of ECMO cannulation were still requiring vasopressor support on ECMO day 3 (45.9\% [17 of 37] to $43.2 \%$ [16 of 37]); excluding patients on CRRT, serum creatinine (1.5 [0.8$2.6]$ to $1.3[0.8-1.9] \mathrm{mg} / \mathrm{dL} ; P=.038$ ) decreased from the time of ECMO initiation to day 3 of ECMO. White blood cell count (13.5 [IQR, 8.4-17.2] K/uL), ferritin (1103.9

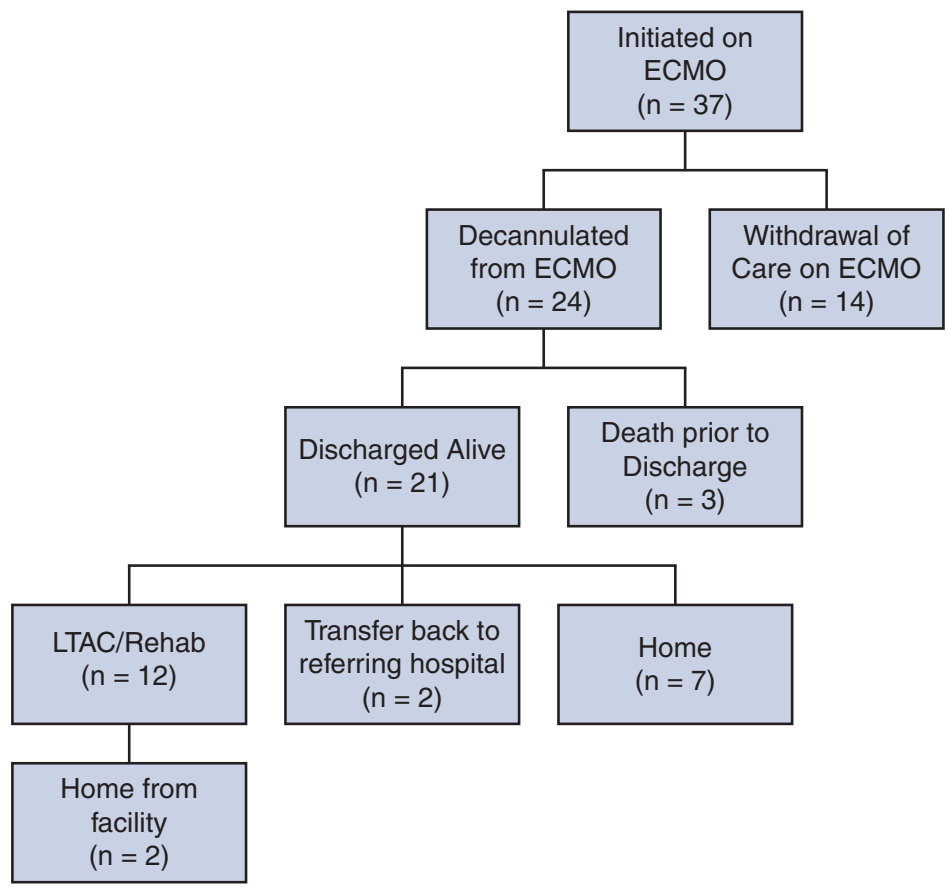

FIGURE 2. Patient flow sheet summarizing clinical outcomes and dispositions of patients with severe acute respiratory distress syndrome associated with COVID-19 who were initiated on venovenous ECMO support. ECMO, Extracorporeal membrane oxygenation; LTAC, long-term acute care. 
TABLE 2. Clinical outcomes of patients with severe acute respiratory distress syndrome associated with refractory COVID-19 who were initiated on venovenous ECMO including use of concurrent therapies and complications related to ECMO

\begin{tabular}{|c|c|}
\hline Survival to discharge from ECMO facility, $\mathrm{n}(\%)$ & $21 / 37(56.8)$ \\
\hline In-hospital mortality, n (\%) & $16 / 37(43.2)$ \\
\hline Death from withdrawal of care on ECMO & $13 / 37(35.1)$ \\
\hline Decannulated from ECMO, n (\%) & $24 / 37(64.9)$ \\
\hline Deceased after decannulation, $\mathrm{n}(\%)$ & $3 / 24(12.5)$ \\
\hline Required tracheostomy & $20 / 26(76.9)$ \\
\hline $\begin{array}{l}\text { Median time from intubation to } \\
\text { tracheostomy, } \mathrm{d}(\mathrm{IQR})\end{array}$ & $19(16.5-25.3)$ \\
\hline Median duration of continuous ventilation, $\mathrm{d}$ (IQR) & $35(20.5-47)$ \\
\hline Median duration of ECLS, d (IQR) & $17(10-33.5)$ \\
\hline Median ICU LOS, d (IQR) & $31(24-51.5)$ \\
\hline Median hospital LOS, d (IQR) & $44(31-62)$ \\
\hline \multicolumn{2}{|l|}{ Concurrent COVID-19 therapy, $\mathrm{n}(\%)$} \\
\hline Hydroxychloroquine & $17 / 37(45.9)$ \\
\hline Azithromycin & $20 / 37(54.1)$ \\
\hline Anti-IL-6 receptor monoclonal antibody* & $25 / 37(67.6)$ \\
\hline Steroids & $26 / 37(70.3)$ \\
\hline Remdesivir & 20/37 (54.1) \\
\hline Systemic anticoagulation & $37 / 37(100)$ \\
\hline Convalescent plasma & $16 / 37(43.2)$ \\
\hline \multicolumn{2}{|l|}{ Concurrent interventions, $\mathrm{n}(\%)$} \\
\hline CRRT & $19 / 37(51)$ \\
\hline Chest tubes & $11 / 37(30)$ \\
\hline \multicolumn{2}{|l|}{ New brain injury, n (\%) } \\
\hline Ischemic & $0 / 37(0)$ \\
\hline Hemorrhagic & $3 / 37(8)$ \\
\hline Coagulopathy (INR >3), n (\%) & $0 / 37(0)$ \\
\hline Liver failure (ALT $>5$ times upper limit), $\mathrm{n}(\%)$ & $5 / 37(14)$ \\
\hline Cardiogenic shock, n (\%) & $2 / 37(5)$ \\
\hline Bacterial pneumonia, $\mathrm{n}(\%)$ & $7 / 37(19)$ \\
\hline Bloodstream infection, n (\%) & $4 / 37(11)$ \\
\hline \multicolumn{2}{|l|}{ ECMO complications, $\mathrm{n}(\%)$} \\
\hline Bleeding & $12 / 37(32)$ \\
\hline Cannula malposition & $1 / 37(3)$ \\
\hline ECMO circuit & $2 / 37(5)$ \\
\hline
\end{tabular}

The total cohort comprised 37 patients; the numerator and denominator (number of eligible patients) for relevant outcomes are listed in the table. In-hospital mortality is calculated from patients who were discharged or died in the hospital. Duration of continuous ventilation, ICU LOS, and hospital LOS calculated from the 21 patients who survived to discharge. Duration of ECLS calculated from the 24 patients weaned to decannulation. $E C M O$, Extracorporeal membrane oxygenation; $I Q R$, interquartile range; $E C L S$, extracorporeal life support; $I C U$, intensive care unit; $L O S$, length of stay; COVID-19, coronavirus disease 2019; CRRT, continuous renal-replacement therapy; INR, international normalized ratio; $A L T$, alanine transaminase. *Administered against placebo in a double-blinded fashion.

[IQR, 489.1-2375] $\mathrm{ng} / \mathrm{mL})$, C-reactive protein (14.1 [7.4-22.8] mg/dL), procalcitonin $(0.7[0.2-2.3] \mathrm{g} / \mathrm{mL}), \mathrm{D}-$ dimer $(2.2[1.5-4.6] \mathrm{mg} / \mathrm{mL})$, and fibrinogen $(534$ [349.8-
$744.5] \mathrm{mg} / \mathrm{dL}$ ) were noted to be grossly elevated on initial presentation before ECMO cannulation. Ferritin and lactate dehydrogenase levels were noted to be down-trending during ECMO. D-dimer was noted to be up-trending during ECMO. There was no clear trend to white blood cell, C-reactive protein, procalcitonin, fibrinogen, and lactic acid across the duration of ECMO. These results are detailed in Table E1.

\section{Clinical Outcomes}

The primary end point of survival to discharge occurred in $56.8 \%$ of patients $(21 / 37)$ (Figure 2). Withdrawal of life-supporting therapies, including ECMO, occurred in $35.1 \%$ of patients $(13 / 37)$ due to futility of care. The remaining 24 of $37(64.9 \%)$ patients were successfully weaned to decannulation of ECMO; $12.5 \%$ of these patients (3/24) died after decannulation. Of these 3 patients, one was noted to have a decline in neurologic status after decannulation and had cardiopulmonary arrest with no return of spontaneous circulation before imaging could be obtained. Two patients had worsening respiratory failure and ultimately went into cardiopulmonary arrest. ECMO was not reinstituted in these patients due to futility of care.

Of the patients discharged alive, 12 of $21(57 \%)$ patients were discharged to a long-term acute care or rehabilitation facility, 2 of $21(10 \%)$ patients were transferred back to the referring hospital for ventilatory weaning, and 7 of 21 $(33 \%)$ patients were discharged directly home. A tracheostomy was required in $56.8 \%$ of patients (20/37). The median duration of time from intubation to tracheostomy was 19 days (IQR, 16.5-25.3). Among the 21 patients who survived to hospital discharge, the median duration of continuous ventilator support was 35 days (IQR, 20.547), ICU LOS at the ECMO center was 31 days (IQR, 2451.5), and total LOS at the ECMO center was 44 days (IQR, 31-62). Patients weaned to decannulation spent a median of 17 days (IQR, 10-33.5) on ECMO. These outcomes are summarized in Table 2.

\section{Complications}

During ECMO support, 3 patients $(8 \%)$ developed hemorrhagic brain injury, 5 patients $(14 \%)$ experienced liver failure, and 2 patients $(5 \%)$ were in cardiogenic shock. No patients developed coagulopathy as defined by an elevated international normalized ratio. Concurrent infection with COVID-19 included bacterial pneumonia in 7 patients $(19 \%)$ and bacteremia in 4 patients $(11 \%)$. ECMO-specific complications included bleeding in 12 patients $(32 \%)$, cannula migration in 1 patient $(3 \%)$, and circuit malfunction in 2 patients $(5 \%)$. Locations of bleeding while on ECMO support included gastrointestinal tract in 7 patients (58.3\% of bleeds), brain hemorrhage in 3 patients (30\% of bleeds), tracheal bleeding in 1 patient $(10 \%$ of bleeds), and retroperitoneal bleed in 1 patient $(10 \%$ of 


\section{Venovenous Extracorporeal Membrane Oxygenation for Patients with Refractory Covid-19: Multicenter Experience of Referral Hospitals in a Large Healthcare System}

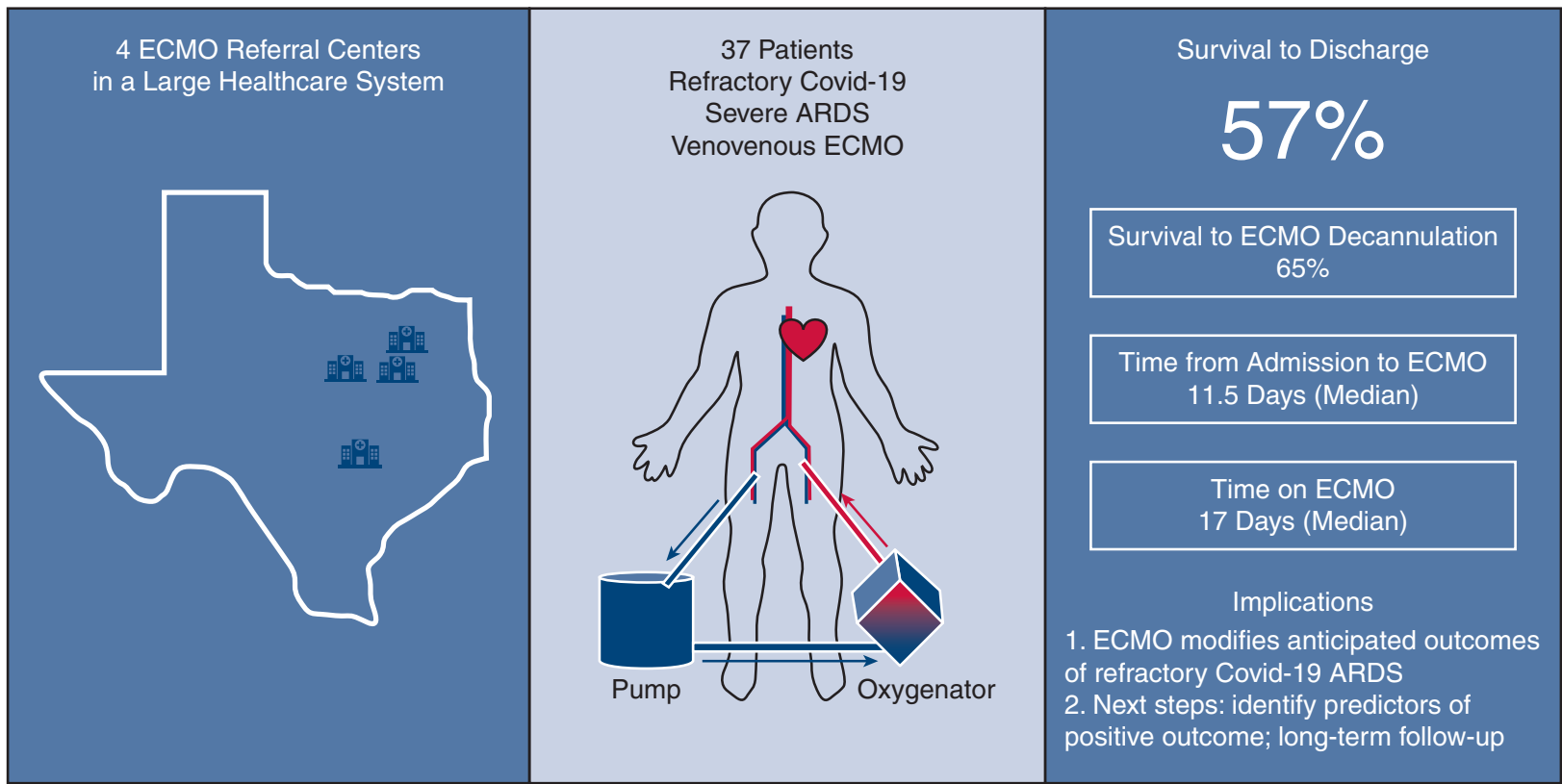

FIGURE 3. Summary of key study findings. A total of 37 patients admitted with severe acute respiratory distress syndrome associated with COVID-19 were initiated on VV ECMO support at 1 of 4 ECMO referral hospitals within a large health care system. Initiation of ECMO occurred on median day 11.5 following admission, and, of the successfully decannulated patients, median time on ECMO was 17 days. Survival to discharge from ECMO center has occurred in 21 of 37 patients (56.8\%). COVID-19, Coronavirus disease 2019; ECMO, extracorporeal membrane oxygenation; ARDS, acute respiratory distress syndrome.

bleeds). Of the 12 patients who had hemorrhage from ECMO-related complications, $9(75 \%)$ are deceased. Of the 3 patients that survived ECMO-related bleeding events, one had scattered small intracranial hemorrhages that caused encephalopathy, another had a retroperitoneal bleed that underwent multiple explorations in the operating room, and the last patient had a gastric bleed that underwent embolization by interventional radiology.

\section{DISCUSSION}

Critical cases of COVID-19-related ARDS present with rapidly progressing respiratory and cardiac failure. There are limited data available regarding the outcomes of ECMO for patients with COVID-19 who continue to progress toward cardiopulmonary collapse..$^{5-7}$ Our study demonstrates that the use of VV-ECMO support modifies anticipated outcomes for patients objectively refractory to medical management and conventional lung-protective ventilatory support (Figure 3). Specifically, of 37 patients initiated on VV-ECMO in this health care system, 21 $(56.8 \%)$ survived to discharge, and $24(64.9 \%)$ were successfully decannulated from ECMO (Figure 4). This population of patients with critical, refractory COVID-19 infection was unlikely to survive without ECMO. Most of the patients were discharged to a long-term acute care or rehabilitation facility for deconditioning and further ventilatory weaning. Although these outcomes represent a slightly lower survival than normally anticipated with ECMO support for ARDS not related to COVID-19, it compares very favorably with published survivals for intubated patients with COVID-19. ${ }^{11,12}$

Our data depict the clinical course one of the largest cohort of patients known to the authors with ventilatoryrefractory COVID-19 salvaged with VV ECMO. ECMO improved the overall hemodynamics and respiratory status of patients, as demonstrated by decreased plateau pressures, partial pressure of arterial carbon dioxide, and vasopressor support requirements over time. Very limited peer-reviewed data are available for comparison with our cohort. Jacobs and colleagues ${ }^{5}$ report on 32 patients at multiple centers throughout the United States, with 1 patient surviving to discharge, although the majority of patients remained on ECMO at the time of publication. Yang and colleagues ${ }^{6}$ reported on 6 patients, with only 1 patient surviving to hospital discharge. Osho and colleagues ${ }^{7}$ described their experience with 6 patients at a single center including 1 death on ECMO, 4 successful ECMO decannulations, and 1 patient surviving to hospital discharge, with 4 remaining hospitalized. Finally, Kon and colleagues ${ }^{8}$ have reported on 27 patients at New York University, of whom 7 (26\%) survived to discharge with the majority of the remaining patients alive but still on ECMO support. The Extracorporeal 


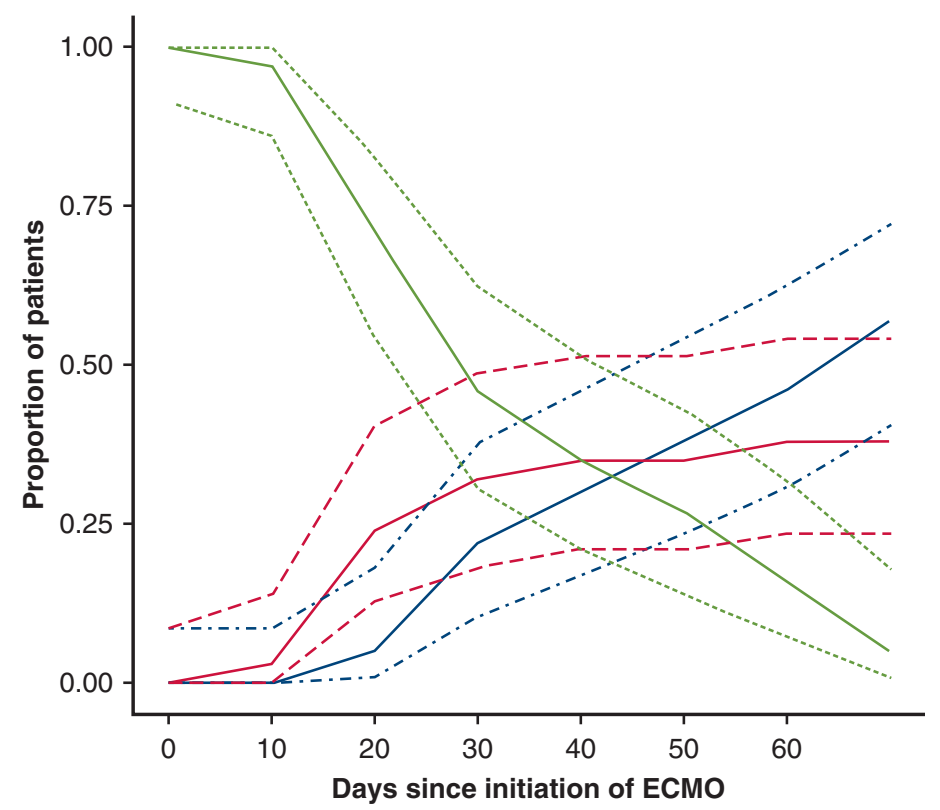

Number at Risk

(Cumulative Number of Events)

$$
\begin{aligned}
& \begin{array}{lllllll}
37 & 36 & 26 & 17 & 13 & 10 & 6
\end{array}
\end{aligned}
$$

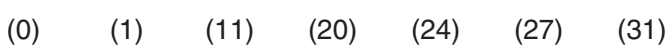

$$
\begin{aligned}
& \text { Decannulated Deceased }
\end{aligned}
$$

FIGURE 4. Competing outcomes over time for patients with severe acute respiratory distress syndrome associated with COVID-19 initiated on venovenous ECMO. Number at risk includes patients remaining on ECMO support, whereas cumulative events included decannulation from ECMO or death (whichever occurred first). Dotted lines represent confidence intervals. ECMO, Extracorporeal membrane oxygenation.

Life Support Organization registry recently reported 588 of 968 patients $(61 \%)$ placed on ECMO for COVID-19 have survived to discharge. ${ }^{13}$ Notably, their reported survival to discharge rate corresponds well with the rate we report from our health care system.

In patients with COVID-19 with severe ARDS, respiratory distress seems to have a rapid onset of progression. ${ }^{14,15}$ In our study, the median length of time from admission to intubation was 1 day. ECMO was typically initiated between 4 and 7 days after the patients were intubated. All patients were in or near extremis at the time ECMO was initiated. During the study period, an additional 2 patients, who were excluded from our analysis, were initiated on venoarterial ECMO. We preferred VV-ECMO for initial support in most cases because the majority of hemodynamic instability exhibited by these patients was attributed to respiratory acidosis resultant from the ongoing ARDS process, which rapidly resolved on after initiation of VV-ECMO.

We notably performed ECMO cannulation at bedside in all 37 patients without immediate complications, suggesting that cannulation can be performed safely even during emergent situations of rapid clinical deterioration. Most patients were initially cannulated in a bifemoral configuration; however, some cannulators elected for bicaval dual lumen internal jugular cannulation. Although there are inadequate numbers to make comparisons, both techniques appear to be technically safe. A subset of the patients underwent operative ECMO revision, typically from bifemoral to internal jugular, to promote patient mobilization. These patients worked with a team of physical therapists, nursing staff, and ECMO specialists to sit at the edge of the bed, transfer to a chair, or ambulate with a walker. Patients unable to tolerate standing or ambulation participated in active range of motion and strengthening exercises while supine. Ultimately, 7 of $37(19 \%)$ of patients were discharged directly home, which likely reflects underlying patient premorbid reserve along with an aggressive physical therapy and mobilization strategy, even while on ECMO support.

Interpretation of the results of this study is limited by the size of cohort and the short-term follow-up limited primarily to hospital outcomes. It is also difficult to determine what, if any, positive or negative effects the concurrent experimental medical therapies may have had on complication rates and overall mortality. Recognizing that ECMO is a resource-intensive therapy, future work should focus on identifying which patients are most and least likely to benefit from ECMO support to better inform clinical decision-making when considering initiation of ECMO 
in a deteriorating patient with COVID-19. Long-term outcomes of ECMO survivors are also essential to ascertain, although no such data are currently available.

This report summarizes novel data from a large health care system with multiple centers managing patients with refractory COVID-19 ARDS using ECMO support. Our findings suggest that ECMO use may be a reasonable treatment option in these cases. Further studies addressing ECMO use in COVID-19 are needed to confirm these findings.

\section{Conflict of Interest Statement}

The authors reported no conflicts of interest.

The Journal policy requires editors and reviewers to disclose conflicts of interest and to decline handling or reviewing manuscripts for which they may have a conflict of interest. The editors and reviewers of this article have no conflicts of interest.

\section{References}

1. Huang C, Wang Y, Li X, Ren L, Zhao J, Hu Y, et al. Clinical features of patients infected with 2019 novel coronavirus in Wuhan, China. Lancet. 2020;395: 497-506.

2. Squiers JJ, Lima B, DiMaio JM. Contemporary extracorporeal membrane oxygenation therapy in adults: fundamental principles and systematic review of the evidence. J Thorac Cardiovasc Surg. 2016;152:20-32.

3. Peek GJ, Mugford M, Tiruvoipati R, Wilson A, Allen E, Thalanany MM, et al. Efficacy and economic assessment of conventional ventilatory support versus extracorporeal membrane oxygenation for severe adult respiratory failure (CESAR): a multicentre randomised controlled trial [published correction appears in Lancet. 2009;374:1330]. Lancet. 2009;374:1351-63.

4. Noah MA, Peek GJ, Finney SJ, Griffiths MJ, Harrison DA, Grieve R, et al. Referral to an extracorporeal membrane oxygenation center and mortality among patients with severe 2009 Influenza A (H1N1). JAMA. 2011;306: 1659-68.

5. Jacobs JP, Stammers AH, St Louis J, Hayanga JWA, Firstenberg MS, Mongero LB, et al. Extracorporeal membrane oxygenation in the treatment of severe pulmonary and cardiac compromise in coronavirus disease 2019: experience with 32 patients. ASAIO J. 2020;66:722-30.

6. Yang X, Yu Y, Xu J, Shu H, Xia J, Liu H, et al. Clinical course and outcomes of critically ill patients with SARS-CoV-2 pneumonia in Wuhan, China: a singlecentered, retrospective, observational study. Lancet Respir Med. 2020;2600: 30079.

7. Osho AA, Moonsamy P, Hibbert KA, Shelton KT, Trahanas JM, Attia RQ, et al. Veno-venous extracorporeal membrane oxygenation for respiratory failure in COVID-19 patients: early experience from a major academic medical center in North America. Ann Surg. 2020;272:e75-8.

8. Kon ZN, Sith DE, Chang SH, Goldenberg RM, Angel LF, Carillo JA, et al. Extracorporeal membrane oxygenation support in severe COVID-19. Ann Thorac Surg. July 17, 2020 [Epub ahead of print].

9. Definition Task Force ARDS, Ranieri VM, Rubenfeld GD, Thompson BT, Ferguson ND, Caldwell E, et al. Acute respiratory distress syndrome: the Berlin definition. JAMA. 2012;307:2526-33.

10. Hochman JS, Sleeper LA, Godfrey E, McKinlay SM, Sanborn T, Col J, et al Should we emergently revascularize occluded coronaries for cardiogenic shock: an international randomized trial of emergency PTCA/CABG-trial design. The SHOCK trial study group. Am Heart J. 1999;137:313-21.

11. Combes A, Hajage D, Capellier G, Demoule A, Lavoue S, Guervilly C, et al Extracorporeal membrane oxygenation for severe acute respiratory distress syndrome. N Engl J Med. 2018;378:1965-75.

12. Bhatraju PK, Ghassemieh BJ, Nichols M, Kim R, Jerome KR, Nalla AK, et al Covid-19 in critically ill patients in the Seattle region-case series. $N$ Engl J Med. 2020;382:2012-22.

13. Barbaro RP, Maclaren G, Boonstra PS, Iwashyna TJ, Slutsky AS, Fan E, et al Extracorporeal membrane oxygenation support in COVID-19: an international cohort study of the Extracorporeal Life Support Organization registry. Lancet. 2020;396:1071-8.

14. Goh KJ, Choong MC, Cheong EH, Kalimuddin S, Wen SD, Phua GC, et al. Rapid progression to acute respiratory distress syndrome: review of current understanding of critical illness from COVID-19 infection. Ann Acad Med Singapore. 2020; 49:108-18.

15. Shi H, Han X, Jiang N, Cao Y, Alwalid O, Gu J, et al. Radiological findings from 81 patients with COVID-19 pneumonia in Wuhan, China: a descriptive study. Lancet Infect Dis. 2020;20:425-34.

Key Words: coronavirus (COVID-19), acute respiratory distress syndrome (ARDS), extracorporeal membrane oxygenation (ECMO), critical care 


\section{APPENDIX E1. CLINICAL INDICATIONS FOR EXTRACORPOREAL MEMBRANE OXYGENATION (ECMO)}

Clinical indications for initiation of ECMO included patients with escalation to and/or maximal ventilation settings defined as a respiratory rate of 30 , inspiratory pressure of 30 $\mathrm{cmH}_{2} \mathrm{O}$, fraction of inspired oxygen $\left(\mathrm{FiO}_{2}\right) \geq 80 \%$, or positive end-expiratory pressure (PEEP) $\geq 10 \mathrm{cmH}_{2} \mathrm{O}$ with any of the following: (1) peak or plateau pressure $\geq 30 \mathrm{cmH}_{2} \mathrm{O}$, (2) partial pressure of arterial oxygen $\left(\mathrm{PaO}_{2}\right) / \mathrm{FIO}_{2}$ less than $100 \mathrm{~mm} \mathrm{Hg}$ with PEEP $10 \mathrm{~mm} \mathrm{Hg}$, or (3) $\mathrm{pH}$ less than $7.15 \mathrm{and} /$ or partial pressure of arterial carbon dioxide $70 \mathrm{~mm} \mathrm{Hg}$; patients on 2 or more vasopressors/inotropes with any of the following: (1) urinary output $<30 \mathrm{~mL} / \mathrm{h}$, (2) mixed venous oxygen saturation $<60 \%$, or (3) lactate $\geq 2 \mathrm{mmol} / \mathrm{L}$.

Early in the course of the COVID-19 pandemic, the Baylor Scott \& White ECMO Governance Council decided to modify the previously established system protocols guiding patient selection for ECMO to patients with COVID-19 for resource stewardship, as recommended by the Extracorporeal Life Support Organization. ${ }^{\text {E1 }}$ Exclusion criteria for all forms of ECMO included age older than 65 years (prepandemic: 75 years), active do not resuscitate status order, evidence of severe neurologic injury, unwitnessed cardiac arrest or ongoing cardiopulmonary resuscitation exceeding 30 minutes, and known malignancy with predicted survival less than 1 year. Body mass index (BMI) $>45 \mathrm{~kg} / \mathrm{m}^{2}$ was considered a relative contraindication (prepandemic: no weight limitation). Exclusion criteria for venovenous ECMO included respiratory failure with advanced septic shock involving 3 or more of the following features: lactate $>10 \mathrm{mmol} / \mathrm{L}$, severe myocardial depression, use of norepinephrine $>1.5 \mu \mathrm{g} / \mathrm{kg} / \mathrm{min}$ or a vasopressor of equivalence, or advanced microcirculatory failure with severe mottling or established purpura. Exclusion criteria for venoarterial ECMO included: unrepaired aortic aneurysm, unrepaired severe aortic or mitral valve regurgitation with poor left ventricular function, severe chronic pulmonary arterial hypertension, or late cardiogenic shock (with 2 or more of the following features: lactate $>15 \mathrm{mmol} / \mathrm{L}$, aspartate transaminase or alanine transaminase $>2000 \mathrm{U} / \mathrm{L}$, international normalized ratio $>4.5$, or advanced microcirculatory failure with severe mottling or established purpura). Importantly, concomitant acute kidney injury was not considered an exclusion criterion as has been adopted at other major centers. $^{\text {E2-E6 }}$

\section{ECMO SETTINGS}

Institutional "rest" ventilator settings were based on the published literature as well as our own experience with several hundred patients with acute respiratory distress syndrome. Our current protocol included a pressure control mode ventilation with a driving pressure (calculated by subtracting PEEP from plateau pressure) of $10 \mathrm{cmH}_{2} \mathrm{O}$, PEEP of $10 \mathrm{~cm} \mathrm{H}_{2} \mathrm{O}$ for BMI $<35,12 \mathrm{~cm} \mathrm{H}_{2} \mathrm{O}$ for BMI $35-40$, and $15 \mathrm{cmH}_{2} \mathrm{O}$ for $\mathrm{BMI}>40$, respiratory rate 10 , inspiratory pressure of $10 \mathrm{cmH}_{2} \mathrm{O}$ (target tidal volume $4 \mathrm{~mL} / \mathrm{kg}$ ), and inspiratory to expiratory ratio of $1: 1.5$. $\mathrm{FIO}_{2}$ was weaned toward the goal of $50 \%$ to maintain $\mathrm{PaO}_{2}$ $>60$. Rate and, occasionally, driving pressure or PEEP were used when ECMO sweep gas rate alone could not compensate for $\mathrm{pH}<7.3$. Although some Asia Pacific ELSO centers tolerate lower oxygenation, oxygenation target in our system was defined as oxygen saturation $\left(\mathrm{SpO}_{2}\right) \geq 88 \%$ based on historical practices. Clinically worsening of oxygenation or carbon dioxide elimination was addressed by adjusting the level of ECMO support. Change in ventilatory settings was used when ECMO support was at its highest level possible. ${ }^{\mathrm{E} 2, \mathrm{E} 4, \mathrm{E} 7-\mathrm{E} 13}$

\section{ANTICOAGULATION ON ECMO}

Administration of a heparin bolus of 50 to $100 \mathrm{U} / \mathrm{kg}$ was given intravenously after successful insertion of ECMO cannula guidewires but before insertion of the drainage and return cannulas. A heparin bolus was repeated if unable to successfully cannulate a patient after 45 minutes. A heparin intravenous infusion of $500 \mathrm{U} / \mathrm{h}$ or $20 \mathrm{U} / \mathrm{kg} / \mathrm{h}$ was started within 30 minutes of ECMO initiation if there was no active bleeding. Heparin was titrated to a goal partial thromboplastin time (PTT) 40 to 60 seconds per historical practice. This target was arbitrarily increased to PTT 55 to 65 seconds, with greater reported thrombosis rates as the pandemic progressed. The target was eventually converted to an anti-Xa assay target of 0.2 to 0.4 . Patients with significant thrombocytopenia (generally platelet count $<50,000 / \mathrm{uL}$ ) were checked for heparin-induced thrombocytopenia with antiplatelet factor 4 antibodies. If antiplatelet factor 4 antibodies were present (dichotomously as positive vs negative, given the Food and Drug Administration guidance to not report optical density), the patient was switched to argatroban at 0.4 to $0.8 \mu \mathrm{g} / \mathrm{kg} / \mathrm{min}$ and titrated to goal PTT pending serotonin release assay. Heparin was held for 4 to 6 hours for ongoing major blood loss requiring frequent transfusions with blood products. Heparin was held for 24 hours in the case of a fresh sternotomy with an open chest and nonfatal central nervous system bleeding. ${ }^{\text {E2-E6 }}$

\section{ECMO WEANING PROTOCOL}

Before ECMO weaning attempt, the patient met the following criteria: improved hemodynamics (mean arterial pressure $>65 \mathrm{~mm} \mathrm{Hg}$ ), low or no vasopressor and inotrope therapy (defined as norepineophrine $<0.05 \mu \mathrm{g} / \mathrm{kg} / \mathrm{min}$, vasopressin $<0.04$ units $/ \mathrm{min}$, dobutamine $<5 \mu \mathrm{g} / \mathrm{kg} / \mathrm{min}$, epinephrine $<0.05 \mu \mathrm{g} / \mathrm{kg} / \mathrm{min}$, milrinone $<0.375 \mu \mathrm{g} / \mathrm{kg} /$ $\mathrm{min})$, normalized lactate $(<2 \mathrm{mmol} / \mathrm{L})$, normalizing alanine transaminase and bilirubin, stable creatinine, and adequate 
urine output (if not on continuous renal-replacement therapy). The patients were at ECMO flows 2-4 lpm, gas sweep 1-2 lpm, and $\mathrm{FiO}_{2} 30 \%$ to $50 \%$. Patients demonstrated spontaneous respiratory drive (either while intubated, or is highly selected cases, when awake and preliberated from ventilator). Patients were therapeutically anticoagulated. ECMO gas sweep was weaned to $0.5 \mathrm{lpm}$ and $\mathrm{FiO}_{2} 21 \%$. Once the target ECMO gas sweep and $\mathrm{FIO}_{2}$ were obtained, an arterial blood gas (ABG) was checked after 30 minutes. If the $\mathrm{SpO}_{2}$ remained $>85 \%, \mathrm{PaO}_{2}>50 \%-60 \%$, and $\mathrm{pH}$ $>7.30$, the gas sweep was shut off. A repeat ABG was checked after 30 minutes to ensure the patient was maintaining target $\mathrm{SpO}_{2}, \mathrm{PaO}_{2}$, and $\mathrm{pH}$ levels. For the vast majority of patients who are intubated, ventilator settings were adjusted accordingly. If the patient was unable to tolerate the weaning trial, they are placed back on full ECMO support with another weaning attempt after 24 hours. A successful wean trial was defined as the ability to maintain the following parameters for 6 to 24 hours after the gas sweep "shut-off" trial: $\mathrm{Spo}_{2}>85, \mathrm{PaO}_{2} 50-60 \mathrm{~mm} \mathrm{Hg}, \mathrm{pH}$ $>7.30$ on $\mathrm{ABG}$ and $\mathrm{FIO}_{2}<60 \%$, respiratory rate $<20$, PEEP $<12 \mathrm{cmH}_{2} \mathrm{O}$, plateau pressures $<30 \mathrm{cmH}_{2} \mathrm{O}$, minute ventilation $<15 \mathrm{~L} / \mathrm{min}$ on the ventilator, and mean arterial pressure $>65 \mathrm{~mm} \mathrm{Hg}{ }^{\text {E2-E6 }}$

\section{E-References}

E1. Huang C, Wang Y, Li X, Ren L, Zhao J, Hu Y, et al. Clinical features of patients infected with 2019 novel coronavirus in Wuhan, China. Lancet. 2020;395: 497-506.
E2. Brogan TV, Lequier L, Lorusso R, MacLaren G, Peek G. Extracorporeal Life Support: The ELSO Red Book. 5th ed. Ann Arbor, MI: Extracorporeal Life Support Organization; 2017.

E3. Short BL, Williams L. ECMO Specialist Training Manual. 3rd ed. Ann Arbor, MI: Extracorporeal Life Support Organization; 2010.

E4. Extracorporeal Life Support Organization. ELSO Guidelines for Cardiopulmonary Extracorporeal Life Support, Version 1.4. Ann Arbor, MI: Extracorporeal Life Support Organization; 2017.

E5. The Alfred Health ECMO Guidelines. Available at: http://www.alfredicu.org au/assets/Documents/ICU-Guidelines/ECMO/ECMOGuideline.pdf. Accessed December 11, 2015.

E6. Moazami N, Anandamurthy B, Sale S, Smedira N, Starling R, Soltesz E, et al Cleveland Clinic ECMO Manual. Cleveland, OH: Cleveland Clinic; April 2013.

E7. Acute Respiratory Distress Syndrome Network, Brower RG, Matthay MA, Morris A, Schoenfeld D, Thompson BT, et al. Ventilation with lower tida volumes as compared with traditional tidal volumes for acute lung injury and the acute respiratory distress syndrome. $N$ Engl J Med. 2000;342:1301-8.

E8. Modrykamien AM, Hernandez OO, Im Y, Walters RW, Schrader CL, Smith LE, et al. Mechanical ventilation in patients with the acute respiratory distress syndrome and treated with extracorporeal membrane oxygenation: impact on hospital and 30 day post discharge survival. ASAIO J. 2016;62:607-12.

E9. Schmidt M, Stewart C, Bailey M, Nieszkowska A, Kelly J, Murphy L, et al. Mechanical ventilation management during extracorporeal membrane oxygenation for acute respiratory distress syndrome: a retrospective internationa multicenter study. Crit Care Med. 2015;43:654-64.

E10. Del Sorbo L, Goffi A, Goligher E, Fan E, Slutsky AS. Setting mechanical ventilation in ARDS during VV-ECMO: where are we? Minerva Anestesiol. 2015; 81:1369-76.

E11. Marhong JD, Telesnicki T, Munshi L, Del Sorbo L, Detsky M, Fan E. Mechanical ventilation during extracorporeal membrane oxygenation an international survey. Ann Am Thorac Soc. 2014;11:956-61.

E12. Amato MBP, Meade MO, Slutsky AS, Brochard L, Costa EL, Schoenfeld DA, et al. Driving pressure and survival in the acute respiratory distress syndrome. $N$ Engl J Med. 2015;732:747-55.

E13. Neto AS, Schmidt M, Azevedo LCP, Bein T, Brochard L, Beutel G, et al. Associations between ventilator settings during extracorporeal membrane oxygenation for refractory hypoxemia and outcome in patients with acute respiratory distress syndrome: a pooled individual patient analysis: mechanical ventilation during ECMO. Intensive Care Med. 2016;42:1672-84. 
TABLE E1. Trends of inflammatory markers of patients initiated on ECMO

\begin{tabular}{|c|c|c|c|c|c|}
\hline & $\begin{array}{l}\text { Pre-ECMO } \\
(\mathbf{n}=\mathbf{3 7})\end{array}$ & $\begin{array}{l}\text { ECMO day } 1 \\
(\mathbf{n}=\mathbf{3 7})\end{array}$ & $\begin{array}{l}\text { ECMO day } 3 \\
\quad(\mathbf{n}=\mathbf{3 7})\end{array}$ & $\begin{array}{c}\text { ECMO day } 7 \\
(\mathbf{n}=\mathbf{3 3})\end{array}$ & $\begin{array}{c}\text { ECMO day of } \\
\text { decannulation }(n=24)\end{array}$ \\
\hline WBC, K/uL & $13.5[8.4-17.2]$ & $12.1[7.6-16.4]$ & $10.2[7.6-17.1]$ & $11.6[9.7-16]$ & 11.7 [7.8-15.5] \\
\hline $\mathrm{Cr}$, serum, $\mathrm{mg} / \mathrm{dL}$ & $1.5[0.8-2.6]$ & $1.7[0.8-2]$ & $1.3[0.8-1.9]$ & $1[0.7-1.7]$ & $0.7[0.5-1.4]$ \\
\hline Ferritin, ng/mL & 1103.9 [489.1-2375] & 1041.2 [608.3-2953] & $956.4[486.6-1233.1]$ & $685.2[339-1215.3]$ & $573.3[278.1-747.1]$ \\
\hline $\mathrm{CRP}, \mathrm{mg} / \mathrm{dL}$ & $14.1[7.4-22.8]$ & 12 [3.1-16.9] & $4.3[2.1-10.4]$ & $2.4[0.7-10.2]$ & $5.3[1.3-15]$ \\
\hline Procalcitonin, $\mathrm{ng} / \mathrm{mL}$ & $0.7[0.2-2.3]$ & $1[0.3-3.7]$ & $1[0.3-5.7]$ & $0.5[0.2-1.1]$ & $0.3[0.2-0.6]$ \\
\hline D-dimer, $\mathrm{mg} / \mathrm{mL}$ & $2.2[1.5-4.6]$ & $10.9[3.9-35.5]$ & $7.2[4.6-22.1]$ & $14.5[5-39]$ & $14[5.6-33.3]$ \\
\hline INR & $1.2[1-1.2]$ & $1.2[1.1-1.4]$ & $1.2[1-1.4]$ & $1.3[1-1.3]$ & $1.2[1.1-1.3]$ \\
\hline Fibrinogen, $\mathrm{mg} / \mathrm{dL}$ & 534 [349.8-744.5] & $510.5[400.8-574.5]$ & $334.5[249.8-423]$ & 243.5 [163.8-376.3] & 165 [149-217] \\
\hline $\mathrm{LDH}, \mathrm{u} / \mathrm{L}$ & 446 [348.5-650.5] & $493.5[380.3-659.8]$ & 505 [391-585.3] & 427 [378-614] & $418[363.5-510.8]$ \\
\hline Lactic acid, mmol/L & $1.6[1.2-2.1]$ & $1.6[1.4-2]$ & $1.6[1.2-3]$ & $1.2[1-1.9]$ & $1.4[1.2-2]$ \\
\hline
\end{tabular}

